\title{
Climate change induced decadal variations in hydrodynamic conditions and their influence on benthic habitats of the Estonian coastal sea
}

\author{
Ü. Suursaar, T. Kullas, A. Kovtun, K. Torn \& R. Aps \\ Estonian Marine Institute, University of Tartu, Estonia
}

\begin{abstract}
Above Northern Europe, recent climate change, apart from temperature rise, also manifests as shifts in wind climatology and storminess, which, in turn, influences the marine ecosystem via changes in hydrodynamic regime. Based on meteorological and sea level data from the Estonian weather and tide gauge stations, as well as on hydrodynamic modelling experiments with the shallow sea 2D model and wave hindcast for the period 1966-2009, the study includes an analysis of hydrodynamic changes in the Estonian coastal waters and discussion on their possible influences on the biotic component of the littoral zone. In the practically tideless Baltic Sea, the climate change induced variations include spatially contrasting trends in sea level, wave conditions and turbidity. Changes in thermohaline and oxygen conditions are frequently governed by shifts in wind-driven flow patterns and upwelling zones. Variations in spatial distribution of charophytes can serve as indicators for changes in coastal sea hydrodynamic conditions.
\end{abstract}

Keywords: climate change, sea level, wave hindcast, macroalgae, Baltic Sea.

\section{Introduction}

Climate change is a complex and spatially varying phenomenon, which may manifest through virtually every measurable meteorological or oceanographic parameter. It influences the marine ecosystem via various links and mechanisms. In the Baltic Sea region, evident climatologic changes appear as an increase in winter and spring air temperatures, decrease in winter ice extent, increase in precipitation and fresh water runoff $[1,2]$; more or less, they all correlate with the NAO-index $[2,3]$. As one of the largest brackish seas in the world, the Baltic 
Sea is a semi-enclosed basin with a total area of $415000 \mathrm{~km}^{2}$, a volume of $21700 \mathrm{~km}^{3}$ and an average depth of $50 \mathrm{~m}$ [1]. Being practically tideless, the Estonian coastal sea (Fig. 1) is a relatively shallow (typically 2-20 m) and considerably indented transition area with salinity varying around 2-8 psu.

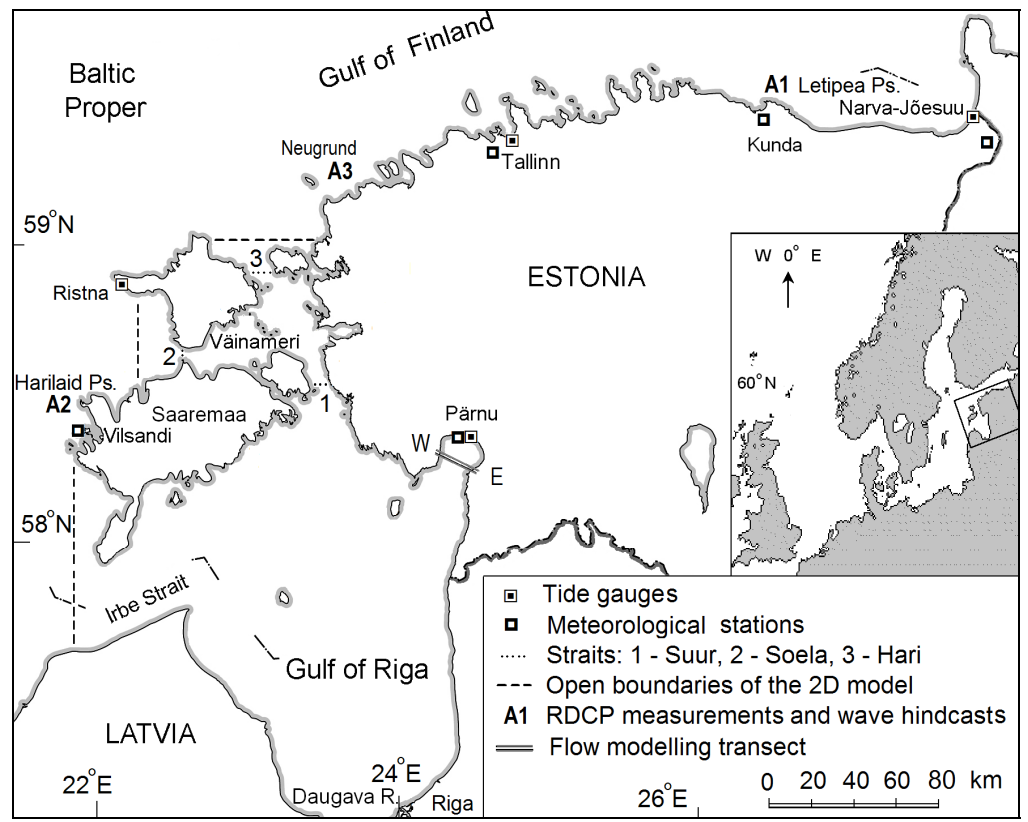

Figure 1: Map of the study area with selected meteorological and tide gauge stations, boundaries of the 2D hydrodynamic model, flow modelling transect, locations of RDCP moorings and wave hindcast.

Above Northern Europe, the climate change also manifests as shifts in wind climatology and storminess [2, 4, 5], which besides regional expressions of global warming, should be considered as the second major climatological driver for changes in biota. Changes in wind forcing conditions and storminess should have a direct influence on the hydrodynamic regime, which generally include:

(1) sea level regime (trends in averages and extremes, storm surge statistics),

(2) wave climates (average and extreme wave fields and their trends),

(3) current regimes (wind-driven circulation patterns, current speeds, shifts and statistics in up- and downwelling zones).

The first motivation of the article is to study meteorologically forced major hydrodynamic phenomena in a shallow semi-enclosed shelf sea and to discuss long-term tendencies in their occurrence statistics. Further on, the links and processes between the above-listed hydrodynamic aspects and the biotic component are discussed. They may apply through physical disturbance during wave storms and storm surges, resuspension of bottom sediment, changes in 
thermohaline regimes, mixing and matter exchange. We also discuss whether charophytes, an interesting group of shallow sea macroalgae, can serve as indicators for changes in coastal sea hydrodynamic conditions.

\section{Material and methods}

\subsection{Sea level and wind climate}

Sea level observations in the territory of Estonia began in Tallinn in 1842 . Currently, twelve tide gauges are operated by the Estonian Meteorological and Hydrological Institute (EMHI). The most reliable data, which are based on hourly measurements, come from Pärnu (measurements since 1923), NarvaJõesuu (since 1899), Ristna (since 1950) and Tallinn (discontinued in 1996). Due to non-uniform land uplift, the use of fixed land level benchmarks complicates the time series analysis and comparison of the results. According to the repeated precise levelling data [6], the radial crustal movements in Estonia are mainly influenced by Fennoscandian postglacial rebound and the uplift rates vary between 0.5 and $2.8 \mathrm{~mm} /$ year along the coast. The Baltic Height System used in the tide gauges has its reference zero (also called the Kronstadt zero), which, within a few cm-s approximates the present-time mean sea level of Estonia [3].

To study changes in wind conditions, as well as to force hydrodynamic models, the hourly sustained wind speed data from meteorological stations (operated by the EMHI) at Kunda $\left(58^{\circ} 06^{\prime} \mathrm{N} 23^{\circ} 58^{\prime} \mathrm{E}\right)$ and Vilsandi $\left(58^{\circ} 23^{\prime} \mathrm{N}\right.$ $21^{\circ} 49^{\prime} \mathrm{E}$; Fig. 1) were used since 1966. These are the closest stations to the respective hydrodynamic measuring and modelling sites. Representing the marine wind regimes of the Northern Baltic Proper [7], the Vilsandi station is situated on the westerly exposed side of a small island. This forcing was used for the West Estonian and the Gulf of Riga applications, while the Kunda station provides marine wind forcing for the North Estonian applications.

\subsection{Measurements and simulations of hydrodynamic conditions}

Field studies on hydrodynamic conditions were carried out at three locations in 2006-2010 (Fig. 1). Four moorings with a total duration of 293 days were performed at the Letipea-Kunda site [8] $\left(59^{\circ} 34^{\prime} \mathrm{N} 26^{\circ} 40^{\prime} \mathrm{E}\right)$. Altogether 154 days of measurements were obtained at the Harilaid-Vilsandi mooring site $\left(58^{\circ} 28^{\prime} \mathrm{N}\right.$ $21^{\circ} 49^{\prime} \mathrm{E}$ ) in 20 December 2006-23 May 2007 [7]. Both sites were $1.5 \mathrm{~km}$ off the shore and 11-12 $\mathrm{m}$ deep. The most recent results came from the Neugrund mooring $\left(59^{\circ} 20^{\prime} \mathrm{N} 23^{\circ} 30^{\prime} \mathrm{E}\right)$ in 20 November $2009-24$ April 2010.

The measurements were carried out using an oceanographic measuring complex RDCP-600 by AADI Aanderaa. The $600 \mathrm{kHz}$ instrument applies the Doppler Effect to measure velocity at different depth layers. It is also equipped with temperature, oxygen, turbidity and conductivity sensors; the high accuracy pressure sensor enabled measurement of wave parameters. Significant wave height (Hs), which is the most commonly used wave parameter, is calculated from energy spectrum. It represents the average height of the $1 / 3$ highest waves, 
and is roughly equal to the visually observed "wave height". The RDCP data were used both in studying hydrodynamic features of the Estonian coastal sea, and as a calibration reference for a wave model, which was then used for longterm wave hindcast.

We also reanalyzed some of our previous hydrodynamic modelling results [9]. Obtained with a shallow sea two-dimensional (2D) model of the Gulf of Riga and the Väinameri (Fig. 1), which simulates both sea level and vertically integrated current values depending on local wind stress and open boundary sea level forcing, they were used to explain some mechanisms, such as how changes in wind climates affect sea level and current regimes.

\subsection{Wave hindcast}

The long-term calculations of wave parameters were performed for two coastal regions: Harilaid and Letipea Peninsula (Fig. 1). The SMB-model, also called the significant wave method, is based on the semi-empirical equations of Sverdrup, Munk, and Bretschneider [10]. The main model input is wind speed. Corresponding wind directions were used for calculating fetch distances. Generally, the fetches are prescribed as the headwind distances from the nearest shores for different wind directions, and some kind of procedure for taking into account basin properties in a wider wind sector is applied [11].

For compensating the wind impediment of southern directions at Kunda station and eastern directions at Vilsandi, we had to slightly modify the fetch lengths during calibration procedure. For the hourly-based 39 day calibration at Letipea we obtained nearly the same wave heights, correlation coefficient 0.92 and RMS error $0.22 \mathrm{~m}$ (Fig. 2). Roughly similar values (r=0.88; RMSE=0.23 m) were also obtained in the Harilaid calibration [7, 8]. The site-dependently calibrated model was then used in multi-year (1966-2009) wave hindcasts at a $3 \mathrm{~h}$ interval. The previously published [7] Harilaid hindcast covers 1966-2006, but especially for this article we updated the calculations until the end of 2009.

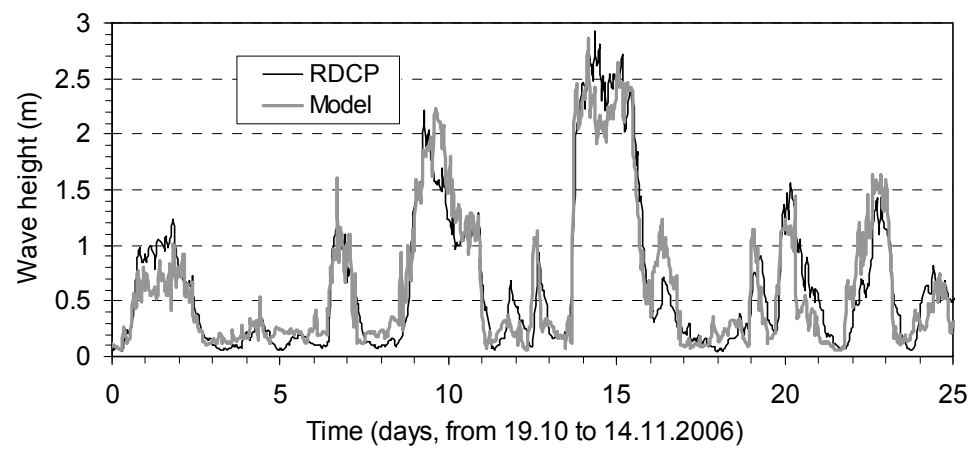

Figure 2: Model calibration: comparison of wave measurements (RDCP) with modelled results near Letipea Peninsula in 2006 (25 days excerpt). 


\subsection{Biotic component of the coastal ecosystem}

The study uses the phytobenthos database of the Estonian Marine Institute, which also includes some data on the abiotic components of the bottom habitat.

The material was collected within the Estonian National Monitoring Programme (phytobenthos sub-programme) in 1995-2010, as well as during some special surveys aimed at mapping charophytes communities [13]. Altogether 8832 locations have been visited, which covers the larger part of the Estonian coasts (Fig. 3a). Sampling has been predominantly performed by SCUBA diving from a boat or directly from the shore. For each locality, its GPS position, depth and sediment type were recorded. The total cover of benthic vegetation and the cover of each macrophyte species were estimated and quantitative samples were collected using a metal frame $(20 \times 20 \mathrm{~cm})$ or an Ekman-type grab sampler $(15 \times 15 \mathrm{~cm})$. The collected macrophytes were packed and frozen until sorting and classification. In the laboratory, species were determined and biomass of charophytes and other species were measured. Within the studied depth range (up to depth of about $30 \mathrm{~m}$ ), vegetation occurred in $93 \%$ of cases and charophytes were present in 1022 locations. In well sheltered and shallow areas, charophytes dominated among the bottom vegetation.

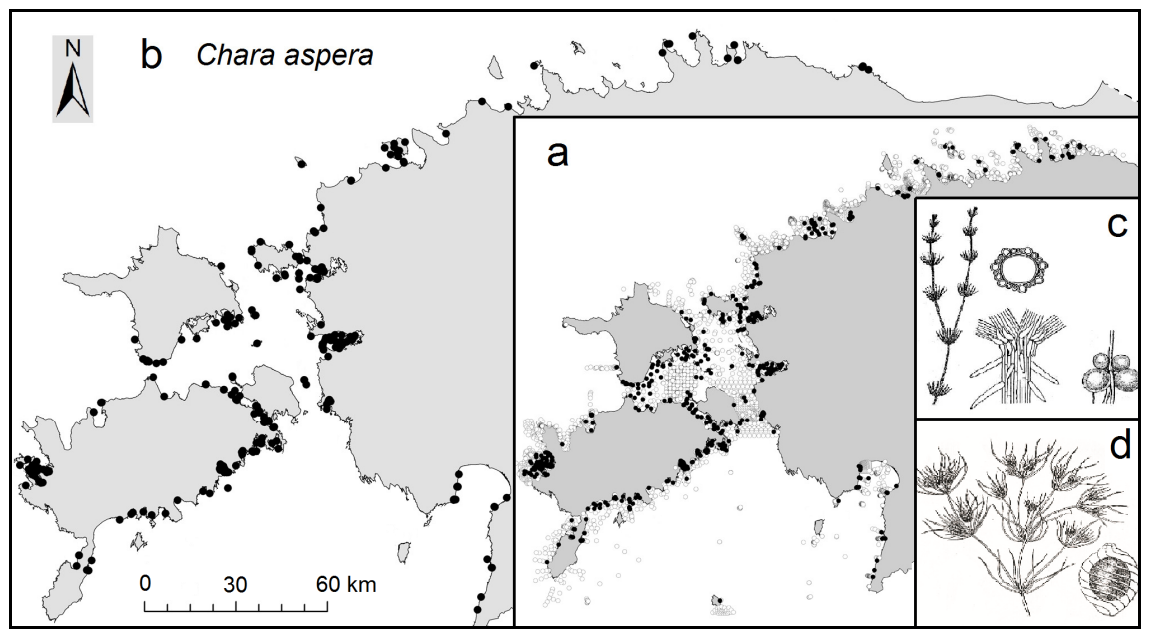

Figure 3: Distribution of charophytes in the study area (a; filled markers charophytes found, empty markers - no findings). Distribution of Chara aspera b); drawings of C. aspera (c) and Tolypella nidifica (d) according to [12].

\section{Results}

\subsection{Long-term variations in mean and extreme sea level}

While the sea level records from Finland and North Sweden exhibit land upliftinfluenced decreasing long-term trends [14], the uplift is considerably smaller in 
Estonia, and the (updated until 2009) time series representing annual mean sea levels show increasing tendencies at Pärnu, Tallinn and Narva-Jõesuu, and yet decreasing trends at Ristna (Fig. 4). Corrected with local uplift rates, the mean sea level rise rates for Tallinn, Narva and Ristna are roughly equal to the global estimates for the 20th century, which were about $1.5-2 \mathrm{~mm} /$ year $[14,15]$. However, even considering possible uncertainties in data quality and land uplift rates, the estimate for Pärnu is significantly higher $(2.4-2.7 \mathrm{~mm} /$ year) than the global one for the same period. The results of our hydrodynamic modelling experiments indicated that in case of an obvious decadal trend in wind conditions, the sea level change rates of a semi-enclosed basin may deviate from the global estimates resulting in a steeper than average sea level trend on the windward side [9]. The crucial role of those changes in wind climate could be confirmed by large change rates in maximum sea levels, ranging between 3.7 and $13 \mathrm{~mm} /$ year (Fig. 4), while the rates in minima are only $0.5-3.4 \mathrm{~mm}$ per year.
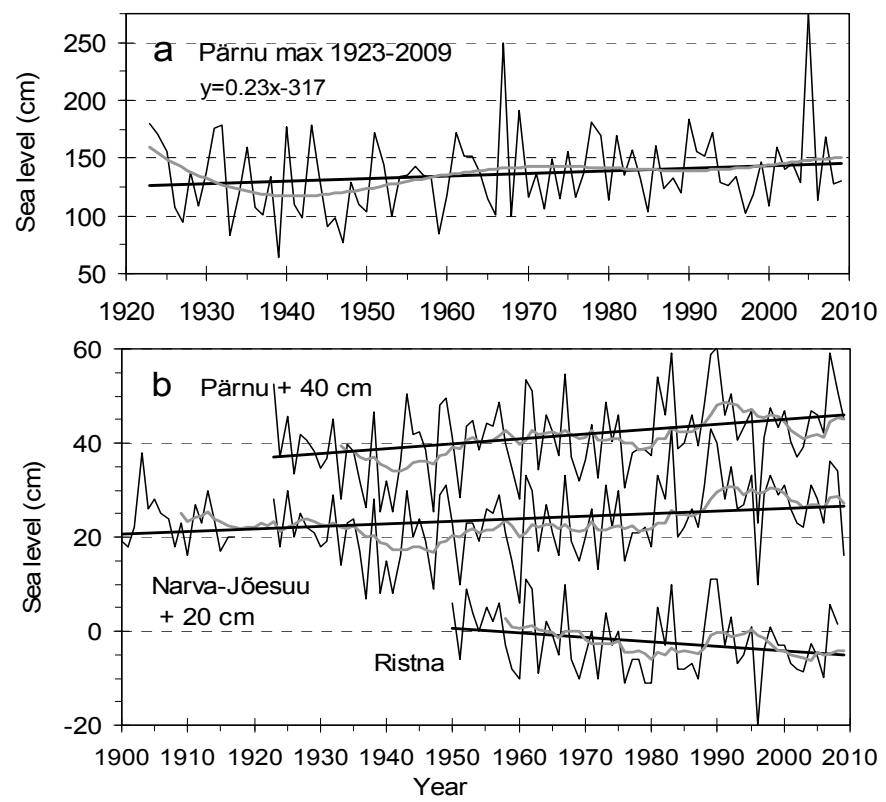

Figure 4: Decadal variations in annual maximum sea level at Pärnu (a) and in annual mean relative sea levels together with 11-year moving averages and linear trendlines (b). The series are not corrected with land uplift rates, and thus exhibit the land uplift together with the climatological sea level rise component.

On the basis of hourly data from 1961-2009, about $90 \%$ of the sea level data fall within the relatively narrow range from -40 to $50 \mathrm{~cm}$ at the Pärnu tide gauge. Still, the sea level variability range is up to $400 \mathrm{~cm}$ (Fig. 5a). Although rare, both extreme high and low sea level events tend to occur in meteorologically more variable winter months (Fig. 5). Strong east winds lower the sea level in the Estonian coastal waters, and west winds increase it. 

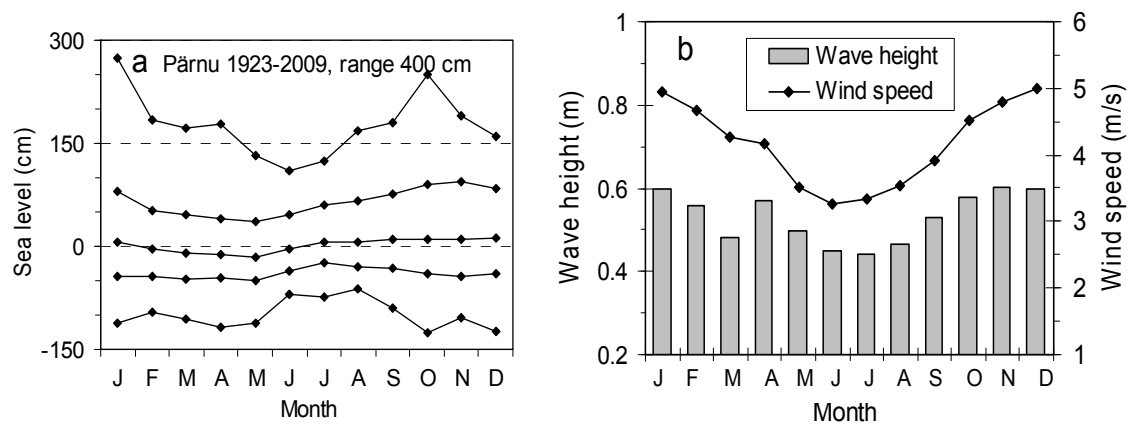

Figure 5: $\quad$ Seasonal variations in monthly sea level statistics at Pärnu (a); lines from top: absolute maximum, average maximum, mean, average minimum, absolute minimum. Seasonality in hourly mean wind speeds and modelled wave heights at Letipea-Kunda (b).

The high sea level events are mainly associated with North European cyclonic storms, which centres bypass Estonia to the north. The strongest winds occur a few hundred kilometres to the right from the cyclone track; small friction above the sea surface and the elongated shape of the Baltic Sea allows strong unobstructed winds to land along the bays of West Estonia [5]. The highest sea level event in the Estonian coastal waters $(275 \mathrm{~cm})$ was registered at Pärnu on 9 January 2005 during cyclone Gudrun. According to modelling runs [9], which considered the $30 \mathrm{~m} / \mathrm{s}$ sustained SW wind and the $70 \mathrm{~cm}$ Baltic background sea level, the maximum sea level may reach $310 \mathrm{~cm}$ at Pärnu. The significantly higher mean sea level rise in winter correlates with increased local storminess during the same months and with the positive phases of the NAO-index [3]. As a result of enhanced seasonal signal and increased maxima, overall sea level variability has also increased, which, in turn, increases turbidity.

\subsection{Wind climate induced changes in flow regimes and wave conditions}

Currents in the study area are determined mainly by the wind and modified by coastline and bottom topography. They are predominantly weak $(5-20 \mathrm{~cm} / \mathrm{s})$ and non-persistent. Only during strong storms, the velocities may reach $1-1.5 \mathrm{~m} / \mathrm{s}$ in certain near-shore areas or straits that funnel the flows [9]. For studying the influence of wind climate changes on currents, the sensitivity runs of the $2 \mathrm{D}$ model used the realistic year 1999 forcing data as the control run, and semirealistic scenario runs used slightly modified wind input [9]. They showed that every change in wind speed or direction affects currents and water exchange between the sub-basins (Fig. 6).

The current speed increases in a strait and along a coastline parallel to the wind direction, and the counter-wind current somewhat increases in the middle of the sub-basin (Fig. 6). Even if the increase in annual mean current speeds makes up roughly $15-20 \%$, it still affects the aquatic environment via exchange processes. As hydrodynamically induced bottom stress is proportional to the square of the flow speed, water turbidity may increase. Near coasts, shifts in upwelling and downwelling zones may occur [9]. In the Baltic Sea, upwelling is 

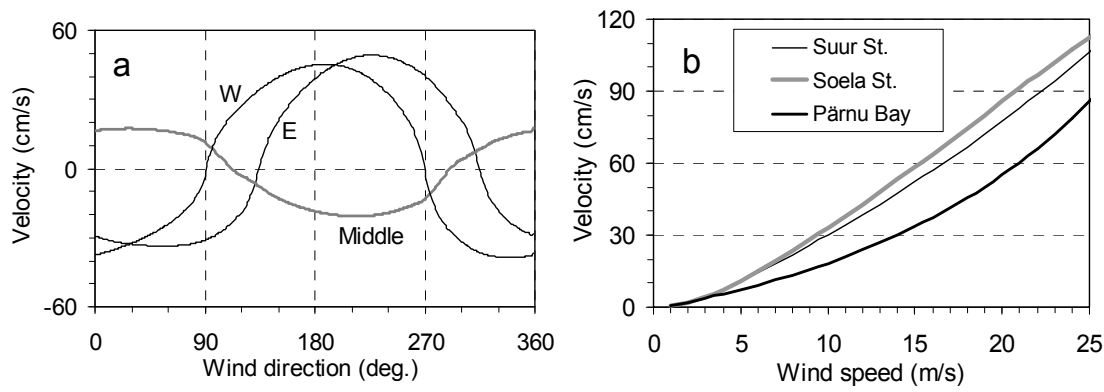

Figure 6: $\quad$ Modelled dependences between the direction of the stationary wind $(20 \mathrm{~m} / \mathrm{s})$ and current moduli in the three locations along the W-E transect in the Pärnu Bay (a). Response of cross-section mean current velocities on the wind (b) blowing along the Suur $\left(160^{\circ}\right)$ and Soela $\left(270^{\circ}\right)$ straits and in the western segment of the Pärnu Bay $\left(220^{\circ}\right)$.

a mesoscale process, which is usually produced by an alongshore wind component with the coast on the left-hand side when looking downwind.

While changes in flow regimes may alter established water column properties, the wave action (Fig. 5b, 7) is the main hydrodynamic agent, which creates direct physical disturbances through movements of water and increases turbidity (Fig. 8). According to the wave hindcasts in the two areas of the Estonian coastal sea, the mean properties of wave heights showed roughly similar quasi-periodic cycles with the last high stage in 1980-1995. However, while at Harilaid the trend in mean wave heights was slightly decreasing in 1966-2009, the trend was steeply decreasing near Letipea $(-0.005 \mathrm{~m} / \mathrm{year}$ in 1966-2008). On the basis of annual maxima, the trends were clearly increasing near Harilaid, but still decreasing near Letipea (Fig. 7). In the middle, the hindcast for the Neugrund (Fig. 1) gave mixed results.

Over the last decades, although the average wind speed has probably decreased both at Vilsandi and Kunda meteorological station, the frequency and strength of storm events have increased at Vilsandi, but decreased at Kunda (Fig. 7). Although slightly increasing, the westerly wind has restricted fetch for the Letipea area, and this component could not keep waves high, while the northerly wind component was decreasing. The increasing storminess at Vilsandi and decreasing strong winds at Kunda $[7,8]$ are probably connected to the changes in atmospheric pressure patterns above North Europe and northward shift of cyclones trajectories over the last decades [2, 8]. There are more cyclones, which bypass Estonia from the north, creating strong westerly winds. On the other hand, there are fewer such cyclones, which cross over Estonia and create strong northerly winds in the course. Naturally, the climate-induced changes are not necessarily similar around the World, and not even within the Baltic Sea. 

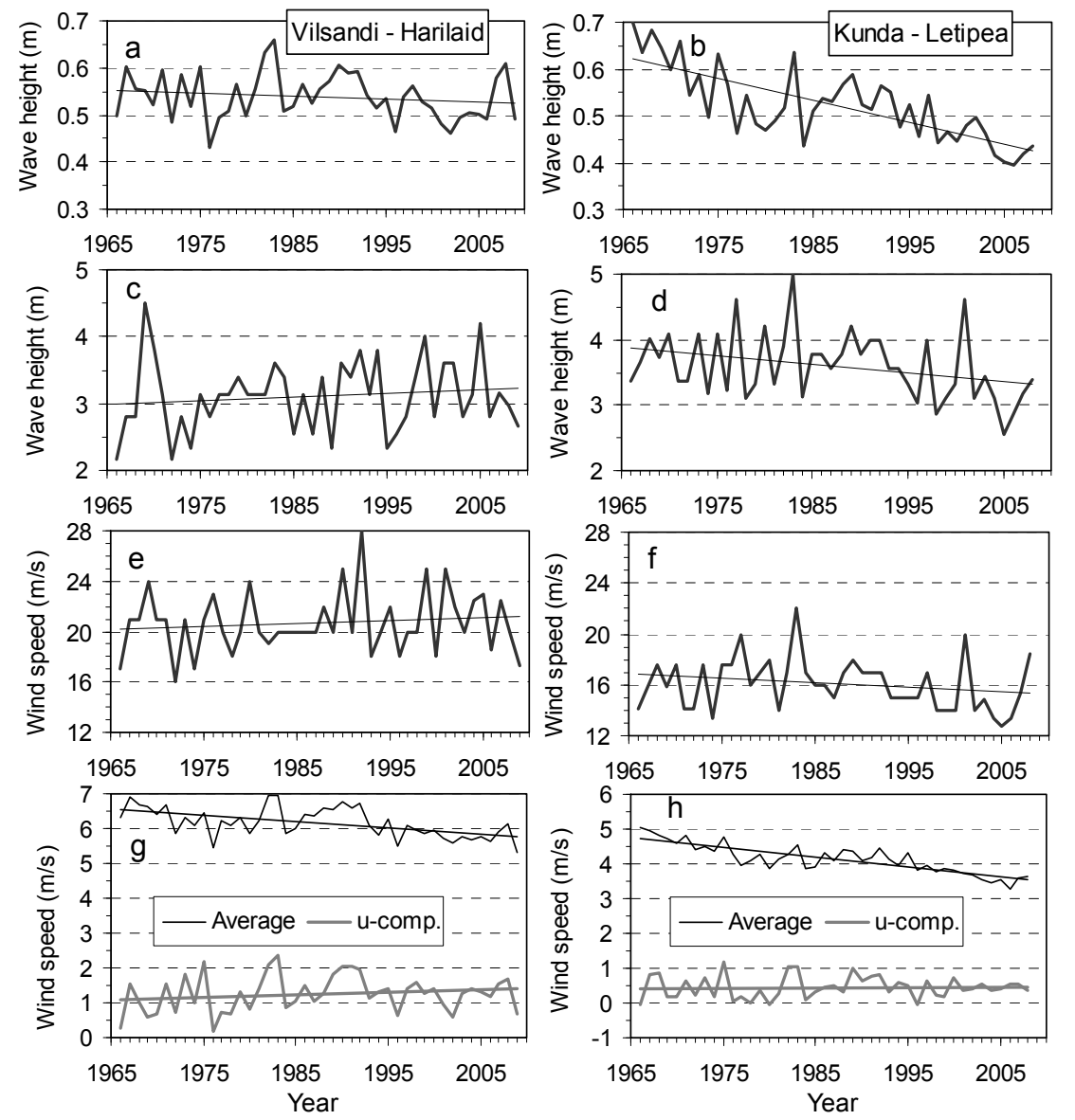

Figure 7: Variations in hindcast annual average $(a, b)$ and maximum wave heights (c, d), measured maximum sustained wind speed (e, f), average and $\mathrm{u}$-component wind velocity $(\mathrm{g}, \mathrm{h})$ at Vilsandi-Harilaid (1966-2009, left panel) and Kunda-Letipea (1966-2008, right).

\subsection{Influence of hydrodynamic processes on biota}

The above discussed hydrodynamic regime changes above the Eastern section of the Baltic Sea may act on the biotic component via several links and mechanisms. In general, hydrodynamic processes mediate water and matter transports between different parts of the sea and shape the local thermohaline and hydrochemical regimes. In fact, the conditions in the whole Baltic Sea are largely controlled by the water exchange with the North Sea. In turn, salinity and temperature play an important role in recruitment dynamics of many fish species [1]. Besides, most of the macrophytes species found in the Estonian coastal waters are sensitive to salinity changes $[13,16]$. In addition to horizontal 
circulation, also occasional upwellings or changes in their occurrence statistics may have a profound impact on water column properties and productivity [8].

During storms, physical disturbance of nearshore bottom habitat occurs [8]. Wave action, turbidity and underwater light conditions are closely related in the Estonian coastal sea until the depths of 10-15 m (Fig. 8). Where soft sediments are available, wave storms may re-distribute sediments; bury bottom vegetation and reproduction grounds of fish. Both strong currents and orbital motions of storm waves may have an influence on spawning and predating of fish. It has been shown [17] that in visual predators, pursuit success decreased with turbulence and long stormy periods may lead to starvation of their larvae.
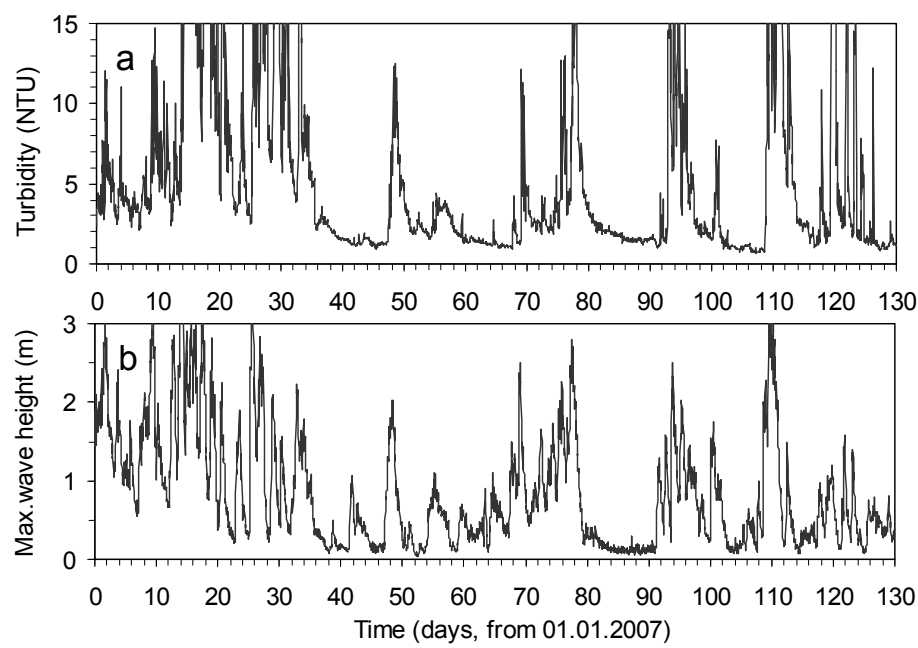

Figure 8: Variations in near-bottom $(11 \mathrm{~m})$ turbidity (a) in dependence from maximum wave heights off Harilaid in 1 January-11 May 2007 (b).

\subsection{Charophytes - indicators for changes in the coastal sea hydrodynamics?}

Charophytes are the most important group of submerged macroalgae found in the shallow and semi-enclosed parts of the Estonian coastal sea (Fig. 3). Besides Charophytes, vascular plants (e.g. Potamogeton pectinatus, Zannichellia palustris and Myriophyllum spicatum) are abundant in these areas [16].

In general, the spatial distribution of charophytes is sensitive to light conditions, salinity, waves, and bottom substrate $[12,13]$. Species-wise, their spatial distribution reflects local hydrodynamic conditions and shifts in their occurrences and coverage may probably be used as indicators for climateinduced changes in hydrology. It appeared that due to the existence of numerous shallow bays and banks within the otherwise hydrodynamically rather active study area, there are still a number of suitable, well-sheltered and soft-bottom habitats for macrophytes. C. aspera (found in 411 locations), T. nidifica (337 locations) and Chara canescens (168 locations) are the most abundant species among the charophytes in the West Estonian coastal sea $[13,16]$. Altogether 7 species of Charales can be found in the Estonian coastal sea. C. aspera (Fig. 3), 
the most frequent plant species of the group, dwell in the coastal zone of the Gulf of Riga and the Väinameri, but also in some bays of the Gulf of Finland and Baltic Proper. It occurs at depths of up to $5 \mathrm{~m}$, prefers silt and sandy bottoms, and tolerates both fresh and brackish water. However, the main reason for such a wide spread is its relatively high tolerance of waves, currents, ice scratch and water level fluctuations. $C$. canescens tolerates salinities in wide range between 1 and 20 , but is sensitive to water movements. $C$. baltica and $C$. connivens are sensitive to eutrophication and turbidity-related diminishing of light conditions.

In most cases, wave and turbidity-connected (Fig. 8) light availability are the most important factors for the distribution of charophytes. Owing to their large thalluses (up to ca $70 \mathrm{~cm}$ ), strong water movements may rip them out of the substrate [18]. In deeper locations, much higher waves can physically occur, but starting from about $10 \mathrm{~m}$, the bottom orbital velocities are damped. Light availability limits charophytes in this zone. Catastrophic events, such as storm surges [5] may destroy their habitats. According to experimental findings [18], the habitat may recover to a nearly equal level in the subsequent season. If such a destruction or burying under redistributed sediment layer becomes too frequent, the whole habitat starts to decline. Higher storm surges, lengthening of ice-free periods in winter and increased turbidity may cause changes in benthic communities. The populations are more likely to survive in well-sheltered bays. It is possible that the observed shifts in storm wind directions, such as decrease in northerly and southerly storms and increase in westerly storms [8], make some of the bays more and others less suitable for charophytes.

\section{Conclusions}

Climate change induced increase in atmospheric westflow and storminess leads to changes in hydrodynamic regime of the sea. Both observations and hydrodynamic modelling results confirm that substantial changes have occurred in the Baltic Sea level, current and wave regimes. There are site-dependent changes in current patterns, mixing conditions and upwelling occurrences. As a result of northward shifts in cyclone trajectories, high waves have increased along the West Estonian coasts, but decreased along the northern coast. The implications of these changes on biotic component of the marine ecosystem and benthic zone apply via physical disturbance, increased turbidity, and through changes in thermohaline and nutrient regimes.

\section{Acknowledgements}

The study was supported by the ESF grant No.7609 and theme SF0180104s08.

\section{References}

[1] BACC. Assessment of Climate Change for the Baltic Sea Basin. SpringerVerlag: Berlin, Heidelberg, 473 pp., 2008. 
[2] Jaagus, J., Post, P. \& Tomingas, O., Changes in storminess on the western coast of Estonia in relation to large-scale atmospheric circulation. Climate Research, 36, pp. 29-40, 2008.

[3] Suursaar, Ü. \& Sooäär J., Decadal variations in mean and extreme sea level values along the Estonian coast of the Baltic Sea. Tellus, 59A, pp. 249-260, 2007.

[4] Keevallik, S. \& Soomere, T., Shifts in early spring wind regime in NorthEast Europe (1955-2007). Climate of the Past, 4, pp. 147-152, 2008.

[5] Suursaar, Ü., Kullas, T. \& Szava-Kovats, R., Wind- and wave storms, storm surges and sea level rise along the Estonian coast of the Baltic Sea. Ravage of the Planet II. Book Series: WIT Transactions on Ecology and Environment, 127, WIT Press: Southampton, Boston: pp. 149-160, 2010.

[6] Vallner, L., Sildvee, H. \& Torim, A., Recent crustal movements in Estonia. J. Geodyn., 9, pp. 215-223, 1988.

[7] Suursaar, Ü. \& Kullas, T., Decadal variations in wave heights off Cape Kelba, Saaremaa Island, and their relationships with changes in wind climate. Oceanologia, 51, pp. 39-61, 2009.

[8] Suursaar, Ü., Waves, currents and sea level variations along the LetipeaSillamäe coastal section of the southern Gulf of Finland. Oceanologia, $\mathbf{5 2}$ pp. 391-416, 2010.

[9] Suursaar, Ü. \& Kullas, T., Influence of wind climate changes on the mean sea level and current regime in the coastal waters of west Estonia, Baltic Sea. Oceanologia, 48, pp. 361-383, 2006.

[10] USACE. U.S. Army Coastal Engineering Research Center, Shore Protection Manual, Vol. 1, Third Ed., U.S. Govt. Printing Office: Washington D.C., 719 pp., 1984.

[11] Massel, S.R., Surface waves in deep and shallow waters. Oceanologia, 52, pp. 5-52, 2010.

[12] Hollerbach, M.M. \& Krasavina, L.K., Freshwater algae of the USSR. Charales - Charophyta. Nauka: St. Petersburg, 190 pp., 1983.

[13] Torn, K., Martin, G., Kukk, H. \& Trei, T., Distribution of charophyte species in Estonian coastal water (NE Baltic Sea). Scientia Marina, 68(S1), pp. 129-136, 2004.

[14] Johansson, M., Boman, H., Kahma, K.K. \& Launiainen, J., Trends in sea level variability in the Baltic Sea. Boreal Env. Res., 6, pp. 159-179, 2001.

[15] Church, J.A. \& White, N.J., A 20th century acceleration in global sea-level rise. Geophysical Research Letters, 33, L01602, 2006.

[16] Martin, G. \& Torn, K., Classification and description of phytobenthic communities in the waters of the West-Estonian Archipelago Sea. Hydrobiologia, 514, pp. 151-162, 2004.

[17] MacKenzie, B.R. \& Kiørboe, T., Larval fish feeding and turbulence: A case for the downside. Limnology and Oceanography, 45, pp. 1-10, 2000.

[18] Torn, K., Martin, G., Kotta, J. \& Kupp, M., Effects of different types of mechanical disturbances on a charophyte dominated macrophyte community. Estuarine, Coastal and Shelf Science, 87, pp. 27-32, 2010. 